\title{
BMJ Open Creating political priority for micronutrient deficiencies: a qualitative case study from Senegal
}

\author{
Yarlini Balarajan
}

To cite: Balarajan Y. Creating political priority for micronutrient deficiencies: a qualitative case study from Senegal. BMJ Open 2014;4: e004784. doi:10.1136/ bmjopen-2014-004784

- Prepublication history and additional material is available. To view please visit the journal (http://dx.doi.org/ 10.1136/bmjopen-2014004784).

Received 2 January 2014 Revised 26 June 2014 Accepted 10 July 2014
CrossMark

Department of Global Health and Population, Harvard School of Public Health, Boston, Massachusetts, USA

Correspondence to Dr Yarlini Balarajan; ysb877@mail.harvard.edu

\section{ABSTRACT}

Objectives: To examine what factors influence the agenda-setting process and level of political priority afforded to micronutrient deficiencies (MNDs).

Design: Qualitative case study employing process tracing, informed by primary data collected from semistructured interviews with policymakers.

Setting: Dakar, Senegal.

Results: Several facilitating and impeding factors affecting the level of political prioritisation for MNDs were identified. Facilitating factors included multiple stakeholders using aligned framing to collectively advocate for MNDs; availability of indicators to quantify issue severity and raise awareness; and transnational advocacy activities around micronutrients. Impeding factors included lack of awareness among policymakers and civil society about MNDs; issue complexity, with the need for coordinated multisectoral response to deliver a complex package of solutions; lack of resources trapping the issue in a 'low-priority' cycle; lack of a policy champion to advocate for the issue and the challenge of demonstrating the effectiveness of interventions to support advocacy efforts.

Conclusions: This study gives insight into the political prioritisation process for MNDs from the perspective of key stakeholders working at the national level in Senegal. In doing so, the study offers some explanation as to why the issue of MNDs has struggled to gain political attention and make it onto the national policy agenda. Moving forward, greater awareness of the factors affecting agenda setting for MNDs may help to devise political strategies to champion this development issue in countries with high burdens of micronutrient deficiencies.

\section{INTRODUCTION}

Vitamin and mineral deficiencies are a leading cause of ill health, affecting vulnerable populations, especially children and women of reproductive age in low-income and middle-income countries. ${ }^{1}$ Deficiencies of iodine, iron, folic acid, zinc and vitamin A are sometimes collectively referred to by the term 'hidden hunger' ${ }^{2}$ - this term, in

\section{Strengths and limitations of this study}

- To the author's knowledge, this is the first exploratory study examining the political prioritisation process for micronutrient deficiencies.

- This study draws on primary data collected from key stakeholders involved in the policy process, and relates the study's findings to the existing theoretical literature to yield some additional insights.

- As with any qualitative case study, it is not possible to generalise the findings to other settings and contexts, although some findings relating to issue characteristics and issue complexity of micronutrient deficiencies may be transferable to other settings.

- The sample size was not large; however, maximum-variation sampling was applied to recruitment to ensure representation from key stakeholders from within and outside national government.

part, reflects the insidious clinical presentation of micronutrient deficiencies (MNDs). Only a small fraction of those affected by MNDs present with overt clinical signs and symptoms, with the majority having subclinical deficiencies. As a result, MNDs can go unnoticed by individuals suffering from them. Despite this 'hiddenness,' MNDs are associated with adverse health and development consequences, contributing to maternal and child mortality and morbidity, physical and intellectual impairment and loss of work productivity, attributing to over 50 million disability-adjusted life years lost globally. ${ }^{3} 4$

Although low-cost, effective interventions to address MNDs exist, progress towards reducing the disease burden associated particularly with iron, folate and zinc deficiencies remains limited, ${ }^{2}$ with mixed progress within and between countries. ${ }^{5}$ Yet, in terms of benefit: cost ratios, interventions to address MNDs are deemed the most favourable of all health and development 
interventions available to improve global welfare. ${ }^{6}$ This raises the interesting and important question of why the issue of MNDs has not generated political priority among national policymakers despite the high disease burden and favourable policy solutions. To the author's knowledge, no previous studies have examined this issue.

Therefore, this study set out to explore the factors determining the national political priority afforded to MNDs. Based on fieldwork conducted in Senegal, it explores how key experts working in nutrition and health perceive the level of political priority afforded to micronutrients in the national health agenda in Senegal, and what factors they consider affect the process of agenda setting for this issue. In Senegal in 2010-2011, an estimated 76\% of children aged 659 months and $54 \%$ of women aged 15-49 years were anaemic; and an estimated $47 \%$ of households consumed adequately iodised salt, ${ }^{7}$ signalling that interventions to address MNDs are needed to reach vulnerable groups.

\section{Agenda setting for global health issues}

$$
\text { "It all depends on politics" }
$$

$$
\text { —Study participant, Dakar, Senegal. }
$$

Health policy in low-income and middle-income countries operates in an increasingly complex environment where global and national actors interact across borders to shape policy and its implementation. The growing numbers of actors, increased connectivity and networks and changing interorganisational relationships are altering the policy process. ${ }^{8}$ A key part of this policy process is agenda setting-the first stage of the policy cyclewhich describes the factors that influence how issues are defined and prioritised on the policy agenda. Expectedly, there is variation of the priority and attention granted to different global health issues. However, it is not fully understood why and what factors drive this variation. $^{9}$

Political scientists and public policy scholars have examined the process by which issues are championed and receive political attention in the agenda-setting stage. Many of these have drawn on Kingdon's theory of agenda setting, where the convergence of three different 'streams' (problem, policy and politics) increases the likelihood of policy success. ${ }^{10}$ More recently, Shiffman and Smith $^{9}$ proposed a framework for the determinants of political priority for global health initiatives. Not theoretically driven, this framework identified 11 variables associated with increased likelihood that a given issue will be placed high on a policy agenda, related to 'actor power', 'ideas', 'political contexts' and 'issue characteristics,' drawing from factors inductively derived from study of the issue of maternal mortality across five countries. $^{9}{ }^{11}$ This work has led to studies that have explored agenda-setting processes related to different global health issues, such as maternal health, newborn health, health systems strengthening and family planning. ${ }^{9} 12-16$

By increasing our understanding of the factors influencing agenda setting, it may be possible to identify opportunities to advance reform and affect the political policy process. Furthermore, by devising political strategies, there is potential to better advocate for hitherto neglected global health issues, such as MNDs. Thus, this knowledge may be one way of responding to the 'Call to Action' from the global health and nutrition community to develop and sustain priority for MNDs on the agenda of national governments. ${ }^{5}$ In 2009, a 'United Call to Action on Vitamin and Mineral Deficiencies' was endorsed by multiple stakeholders working in the field, which set forth the case for investing in addressing MNDs and united global advocacy efforts. The global launch was followed by national launches in four countries, Bangladesh, Kenya, Pakistan and Senegal, in an attempt to increase commitment for MNDs and develop sustainable partnerships between national government and other stakeholders. ${ }^{17}$ The case study of Senegal was selected for this study as this was one of the countries where a national launch of the global call to action was held, providing an opportunity to also explore how global agenda-setting processes influence the national policy process.

\section{METHODS}

This case study used process tracing, a qualitative method used by political and social scientists, that can be applied to assess complex processes where multiple factors may interact to cause effects. ${ }^{18}$ Process tracing is appropriate for within-case analysis and particularly useful for examining complex issues, such as the policy process; and understanding and exploring historical events, such as the national launch of a global 'Call to Action' on MNDs.

Multiple data sources were triangulated to minimise systematic bias: primary data collected from semistructured interviews with high-level representatives from key institutions involved in policymaking; and secondary data from systematic review of government policy documents, national surveys, donor reports and published research relating to MNDs.

Primary data collection was carried out in Dakar, Senegal. High-level representatives involved in policymaking and implementation of policies concerning nutrition and health in Senegal were eligible for inclusion in this study. In order to gauge the widest possible range of stakeholder perspectives, maximum-variation sampling was applied to recruitment. This included perspectives from within and outside national government, with participants from government and non-government organisations (multilateral organisations, bilateral organisation, academic institutions working in the area on MNDs and health) (table 1). 


\begin{tabular}{lll}
\multicolumn{2}{l}{$\begin{array}{l}\text { Table } 1 \text { Characteristics of study participants interviewed } \\
\text { for this study }\end{array}$} & $\mathbf{n}$ \\
\hline Stakeholder & Organisation & 7 \\
\hline $\begin{array}{l}\text { Internal stakeholders } \\
\text { (within government) }\end{array}$ & $\begin{array}{l}\text { Governmental } \\
\text { institutions }\end{array}$ & 1 \\
& $\begin{array}{l}\text { National executive } \\
\text { agency }\end{array}$ & \\
External stakeholders & $\begin{array}{l}\text { Multilateral institutions } \\
\text { (outside government) }\end{array}$ & 3 \\
& $\begin{array}{l}\text { Non-governmental institutions } \\
\text { organisations }\end{array}$ & 1 \\
& $\begin{array}{l}\text { Academia/clinical } \\
\text { medicine }\end{array}$ & 1 \\
& & 15 \\
\hline
\end{tabular}

Potential participants were identified through a number of different sources: (1) literature relating to micronutrients and health to identify the range of key institutions, (2) input from key opinion leaders working in nutrition and health in Senegal to identify individuals from these institutions and (3) snowball sampling, whereby participants were asked whether they could recommend others who may be relevant to the study. Fifteen key institutions were initially identified and potential participants representing these institutions were approached in person or by email and/or telephone in order to set up interviews. Letters of introduction were then emailed informing participants of the purpose of this study and seeking their consent to participate. All 15 individuals approached agreed to be interviewed for the study. Although the participants purposely represent a diverse range of organisations, they share common interests and knowledge in nutrition and health; they were also high-ranking representatives holding leadership positions in their organisations.

Semistructured interviews were conducted in Dakar at the offices of the participants (except for one interview conducted in the USA by telephone) in the summer of 2010. Informed consent was obtained verbally at the start of the interview. These interviews were guided by a prepared survey instrument developed exclusively for this study (see online supplementary table S1), however key experts were encouraged to discuss the issues pertaining to MNDs from their perspectives. The survey included one question designed to gauge the perceived level of political priority for MNDs using a Likert scale. Interviews lasted around 1-2 h. When possible and permitted interviews were recorded, otherwise contemporaneous notes were taken, which were immediately written up following the interview. Interviews were primarily carried out in English, although in some interviews a mixture of English and French was used.

Each of the recorded interviews was transcribed. Interview transcripts and notes were examined and content analysis performed, from which themes relevant to the research question identified. These were coded, applying an emic coding approach, using methodology based on grounded theory. ${ }^{19}$ In order to verify the themes that arose, sections of interview transcripts were also reviewed by other researchers (students enrolled in either masters or doctoral degree programmes taking a qualitative methods course) during the data analysis stage to confirm the reliability of the coding and emergent themes during this inductive process.

These data were then entered into a spreadsheet, where the themes from internal stakeholders (from within the national government institutions) and external stakeholders (from outside national government) were grouped separately. This spreadsheet facilitated further analysis and identification of the perceived factors that facilitated or obstructed political priority for micronutrients.

\section{RESULTS}

The perceived level of political priority for MNDs on the national health agenda varied between participants, within and outside national government. When asked to estimate the current level of priority (very low/low/ medium/high/very high), the level of priority for internal stakeholders ranged from 'very low' to 'high', and for external stakeholders ranged from 'low' to 'high'. Internal stakeholders were more likely to rank the level of priority afforded to MNDs as 'medium' compared with 'high' from external stakeholders. Participants from institutions whose mission was primarily related to nutrition and MNDs were more likely to perceive that MNDs occupied a lower level of priority on the national development agenda.

Several themes emerged from the data analysis, revealing factors affecting the level of national priority afforded to MNDs, and factors affecting the implementation of MND policies. These were classified into facilitating and impeding factors, and ranked according to the frequency with which these were discussed. Facilitating factors were those that promote the creation and/or maintenance of political priority for MNDs, whereas impeding factors were those that curtailed development of political priority for MNDs. These factors are summarised in table 2 , and detailed below.

\section{Factors facilitating agenda setting for micronutrient deficiencies \\ Multiple stakeholders to collectively advocate for the issue}

As in many low-income and middle-income countries, a large network of stakeholders work in nutrition in Senegal. All participants discussed the complexity of the partnerships between stakeholders working in MNDs and the necessary coordination required to achieve results in this sector. This required close coordination between the various divisions in the lead ministry (Ministère de la Santé, de la Prévention et de l'Hygiène Publique, $\mathrm{MOH}$ ), between the $\mathrm{MOH}$ and external stakeholders, and between external stakeholders. The 
Table 2 Identified factors affecting agenda setting for micronutrient deficiencies (MNDs)

\begin{tabular}{ll}
$\begin{array}{l}\text { Factors facilitating } \\
\text { agenda setting for MNDs }\end{array}$ & $\begin{array}{l}\text { Factors impeding } \\
\text { agenda setting for MNDs }\end{array}$ \\
\hline $\begin{array}{l}\text { Multiple stakeholders, with } \\
\text { aligned framing of the } \\
\text { problem, to collectively } \\
\text { advocate for the issue }\end{array}$ & $\begin{array}{l}\text { Issue invisibility: lack of } \\
\text { awareness among } \\
\text { policymakers and civil } \\
\text { society }\end{array}$ \\
$\begin{array}{l}\text { Availability of MND } \\
\text { indicators to raise }\end{array}$ & $\begin{array}{l}\text { Issue complexity: } \\
\text { multisectoral solutions } \\
\text { issue severity } \\
\text { required to address MNDs } \\
\text { Transnational advocacy }\end{array}$ \\
$\begin{array}{l}\text { Lack of adequate resources } \\
\text { to address MNDs: trapped } \\
\text { in a 'low-priority' cycle }\end{array}$ \\
$\begin{array}{l}\text { Lack of a champion to } \\
\text { advocate for the issue and } \\
\text { institutional weakness of the }\end{array}$ \\
$\begin{array}{l}\text { lead ministry } \\
\text { Challenge of demonstrating } \\
\text { effectiveness of } \\
\text { interventions for MNDs to } \\
\text { support advocacy efforts }\end{array}$ \\
\end{tabular}

benefits of multiple stakeholders working towards the same goals were highlighted, in collectively generating attention for the issue, capitalising on their comparative strengths and technical capabilities to champion the issue with national policymakers. This was enabled by the shared understanding of the issue and aligned narrative.

For example, one external institution saw advocacy for MNDs as critical, stating this as part of their mission to increase priority for micronutrients: "the key is to raise awareness and build capacity in the ministry, and to help provide the resources to integrate this [MNDs] into day to day delivery ... by working with other partners we can drive the government to deliver."

The technical expertise and practical assistance from external stakeholders provided great support for this issue at the policy and implementation levels. Internal and external stakeholders commented on the benefits of working together. The close community of technical experts allowed for sharing of knowledge and best practices, and these stakeholders were therefore able to come together to generate a more focused and combined approach to advocate for MNDs to have higher priority of the government agenda.

\section{Availability of MND indicators to raise awareness and quantify issue severity}

Universally participants raised the importance of credible indicators in measuring MNDs' severity and in evaluating and quantifying the impact of programmatic interventions. The Senegal Demographic and Health
Survey, a nationally representative survey that has specific indicators relating to MNDs, was frequently referred to, which may have also reflected the fact that the $\mathrm{MOH}$ and other stakeholders were actively preparing for implementation of the next survey.

The availability of data was also seen as important to raising awareness of and advocating for the issue of MNDs. For example, one external stakeholder explained: "Senegal is trying to move forward in its development. They $[\mathrm{MOH}]$ are trying to look more at the indicators, for example malnutrition is high, and so therefore they want to change this ... Therefore there is high priority of nutrition in the country ..." The timeliness of such data was also important, as one internal stakeholder mentioned: "fresh country results are important." Other internal and external stakeholders discussed the challenges facing the delivery of timely, complete and accurate data from the local level to the ministry and other stakeholders. Participants commonly referred to indicators relating to anaemia (iron deficiency is a major cause of anaemia) and vitamin A, only rarely did they directly comment on iodine and zinc, and none commented directly on folic acid deficiency.

Compared with interest in the Millennium Development Goals (MDG) indicators, interest in MND indicators by policymakers was seen as lacking. As another participant commented: "MDG indicators are on high-level documents and it helps to get financing for these activities and it also helps the government to be aware of nutrition. It was a very good idea [laughs]. But for micronutrients it is lacking, maybe we could improve this ... We could have indicators involving micronutrients."

\section{Transnational advocacy activities around MNDs}

On the whole, participants felt that global policy agendas and policy documents, such as the MDGs, 'United Call to Action on Vitamin and Mineral Deficiencies' or 'Repositioning Nutrition as Central to Development', ${ }^{20}$ did influence the Senegalese national health policy agenda as it relates to nutrition and MNDs. The main mechanism for this was thought to be through financial and technical resources driven by external stakeholders.

Commitments to achieve the MDGs helped to align different stakeholders working in health as to the importance of nutrition in achieving these goals, which has also had a positive impact on addressing MNDs as well. One internal participant said "Nutrition has a role to play in all the [Millennium Development] Goals. It is very important. I think at the beginning [of the MDG process] the role of nutrition was not that clear, but now things are different ... For women and children, it is very very very important to achieve the MDGs." Transnational global health activities have helped with the advocacy for the role of nutrition; one participant expressed this saying, "For MNDs and nutrition globally, we use The Lancet to talk with the authorities. We use 
the global action plan for nutrition. It is a good way, if we use what is going on at the international level in our countries, all those results and all those information as advocacy materials to get political will." Another stated that "with the global agenda, there is evaluation and therefore things are improving," indicating the transnational influence of monitoring and evaluation and achieving targets.

Senegal signed up to the Call to Action on vitamin and MND in January 2010. Support for this came from the highest level within the lead ministry with the Minister of Health and Prevention in Senegal joining with other key stakeholders to launch the report, 'Investing in Senegal's Future: A United Call to Action on Vitamin and Mineral Deficiencies'. This report specifically calls for increased commitment to MNDs, together with the investment in sustainable partnerships between stakeholders. ${ }^{17}$ Although none of the internal stakeholders thought that this had impact on behaviour, the impact perceived by external stakeholders was mixed. For example, one external stakeholder commented, "I think that this [Call to Action] had impact. It reinforced for all stakeholders the importance of micronutrients. There was a real impact and the advantage is that this is the way to advance the agenda and to emphasize the importance." Other external stakeholders thought that the impact was minimal or hard to gauge. Although the severity of MNDs gained the attention of policymakers at the time of the launch, translating this into successful implementation was the main barrier identified by external stakeholders, especially those involved with implementation.

\section{Factors impeding agenda setting for micronutrient deficiencies}

From stakeholder interviews, five key factors were identified that seemed to hinder generation of political priority for MNDs; these are summarised below.

\section{Issue invisibility: lack of awareness among policymakers and civil society}

Stakeholders commented on the particular challenge relating to issue visibility and the 'hiddenness' of MNDs. This extended from policymakers to civil society. As one external stakeholder asked, "Are all the stakeholders aware of the importance of micronutrients? For health? Economic growth? Regarding the well-being of the nation? It is a question of awareness and political will, and maybe a question of difference sectors working all together." Similarly, another external stakeholder commented, "At the policy level, it is a matter of awareness, information, and education on the issue;" while another stated that "At the ministry, there is no decision maker who asks for micronutrient indicators, say compared to immunizations etc." This was contrasted to other global health issues such as maternal mortality and HIV/AIDS where the disease burden and impact were more 'visible'.
Universally stakeholders interviewed agreed that there was a lack of public awareness about nutrition and micronutrients, stating that there has been little attempt to mobilise civil society to press for progress in this issue. Some marketing campaigns were in place and were mentioned, such as fortified foods for infants, and national alliances to promote food fortification, but their impact was not known. This lack of awareness, in part, reflects the subclinical presentation of MNDs. As one internal participant noted, "If you have micronutrient deficiencies you can't see it. Say you have anemia - when you go to the health system you are given medicine but you can't see it - You can have anemia all your life and not know it. The consequences are not visible most of the time." Participants discussed the need to encourage public awareness in the public: for example, "the beneficiaries [civil society] also need to see this and the benefits of results ... you know for comparison, for roads, or for wheels, for water, they see it - they know it - you see that you need it for everything - they see the health huts and health centres and see that. But for micronutrients - you don't see it." Thus for MNDs, the characteristics of the issue and the 'hidden' presentation has implications for its visibility at the policy level and for civil society.

\section{Issue complexity: multisectoral solutions required to address} MNDs

Another challenge participants identified was the multisectoral nature of the necessary interventions to deal with MNDs. This spans ministries and although there is a specific taskforce on addressing malnutrition in Senegal, coordinating a response is difficult. Furthermore, there were inconsistencies in the perceptions of who should take leadership and responsibility for this issue, and what the policy solutions should be. One internal stakeholder expressed the opinion that the $\mathrm{MOH}$ should not be the main overseer of nutrition, as prevention (rather than treatment) should be championed and therefore it should fall most under the remit of the Ministries of Agriculture, Industry and Education. He indicated "It is a multisectoral issue, maybe health is doing its role, but there are other sectors that may not be doing so. I think that in Senegal we need a better approach. We have not yet defined what it should be ... There are different sectors with different responsibilities, and we need to do this exercise to define the issue and then the level of priority. For example, with anemia, you have to work on the agriculture, industry - they all have responsibilities and roles many other sectors - as the $\mathrm{MOH}$ is there to see the problems - it just works on the end." Another participant commented on collaboration between internal and external sectors, saying "We have to join efforts between the $\mathrm{MOH}$ and industry and the private sector - health alone won't be able to reduce this significantly. The $\mathrm{MOH}$ works on the consequences of MNDs, they are at the end, and it's a big deal for the MOH." 
These views reflect the difficulties that extend from the multisectoral nature of the issue in terms of coordinating the complex array of actors working in nutrition and health, and who should take responsibility for overseeing this issue, in terms of prevention versus treatment and public versus private sector involvement. This is further complicated by the different agendas and priorities that these external partners may have. As one internal stakeholder commented, "sometimes you face difficulties as they have different agendas, so you have to have a good sense of flexibility and adaptability as an organization." Operationally, coordination means that much time is spent in meetings and significant ministerial capacity is reportedly spent "in meetings and doing report preparation, rather than the actual work." One external stakeholder commented, "If you go to into X [referring to a $\mathrm{MOH}$ Division], no-one else is there as they are all out with different partners. It is very difficult to manage." All external stakeholders interviewed, however, were sympathetic to the constraints of ministerial capacity to deal with competing priorities and the burden of work, given limited human and operational resources.

\section{Lack of adequate resources to support MNDs: trapped} in a 'low-priority' cycle

Lack of financial, human and physical resources to support MND initiatives and their scaling up was stated as a major challenge to actually realising higher political priority for MNDs. Internal and external stakeholders commented on lack of resources compounding the difficulty of integrating MNDs' policy solutions into the day-to-day delivery of existing programmes, which meant that the issue was stuck in a 'low-priority cycle', ${ }^{21}$ with lack of budgetary commitment to support advocacy efforts for higher prioritisation of the issue.

Interviews with internal stakeholders revealed four challenges: first, inadequate financial commitments to MNDs from the government, which made the $\mathrm{MOH}$ very dependent on external partners to support this agenda. Although necessary, this, in their opinion, had limited the ability to develop and implement a longer term vision for MNDs. Second, [that] "the resources are not sufficient to implement the programs, [and thirdly,] the other is the coordination of existing resources. We need to use these efficiently, with better coordination of the existing resources. We have to do better, and put in enough effort to use resources rationally...It is really important to coordinate better - interventions and resources." Fourth, financing vertical programmes reportedly compromised a more holistic approach to tackle MNDs, and also limited the flexibility for resource allocation.

More positively, new global funds earmarked for nutrition, and the collective support of the external stakeholders meant that gaps in service delivery where possible could be addressed by different partners working together.
Lack of a champion to advocate for the issue and institutional weakness of the lead ministry

A specific issue raised was the lack of an individual or champion to 'push' for MNDs from within the ministry. Building on the preceding theme, lack of resources were felt to further compound the effectiveness of the lead institution. Six out of the eight external stakeholders identified poor leadership capacity of the $\mathrm{MOH}$ as an obstructing factor facing priority setting for MNDs and the development and implementation of related policy solutions, whereas only two of seven internal stakeholders raised this issue. Furthermore, stakeholders commented on the lack of a clear strategic plan for MNDs, with limited leadership capacity to manage the necessary multisectoral response and coordinate multiple stakeholder involvement for MNDs. One external stakeholder commented: "This [MNDs] requires a high level of leadership from the ministry ... there is a certain level of leadership, but this needs to be developed more to bring all available resources to implement the interventions priority, by priority, which should be defined by the MOH. This is really important ..." Similarly, another external stakeholder stated, "It is a question of leadership. They $[\mathrm{MOH}]$ need to have a very strategic plan, it is very important, because with the implementation plan, and with monitoring and evaluation, it is important for the $\mathrm{MOH}$ to coordinate all the support. It is not easy [laughs] ... it is a challenge."

The internal stakeholders who specifically commented on leadership from the lead institution did, however, state how they are attempting to address this issue and build up the ministerial leadership capacity through various training initiatives.

\section{Challenge of demonstrating effectiveness of interventions for MNDs to reinforce advocacy efforts}

Despite the theoretical existence of effective interventions for MNDs, implementation was identified by participants as a key challenge in the Senegalese context. The need to show the effectiveness of interventions was critical, yet difficulties with data and information systems hindered pursuit of this. As an internal stakeholder pointed out, "We have many problems with data. Data is very important to identify better interventions and to allocate resources ... we have some problems, especially at the health facilities level to monitor here-there are sometimes lack of materials to collect such data, and I know the ministry is trying to improve this fact. If we lack data, we will always have problems. This is important for monitoring key indicators, and necessary for operations... All partners are interested in this." The problems with data collection identified by interviewees included the lack of supervision at the community level for collecting data, poor reporting resulting from limited training, capacity, lack of job awareness and lack of transfer of data centrally leading to data and information loss. 
Stakeholders reiterated the importance of demonstrating success to strengthen advocacy: "For advocacy you need results. The best way to advocate is to show results and that it works. At the moment we don't have the evidence to show this ... it is very difficult." The pressure to gather data for monitoring and evaluation to show the effectiveness of their interventions was also highlighted by external stakeholders working on the implementation side. Evaluating the impact of programmes was seen as important for securing continued donor support. "Results can help the process to improve. With results, then they [donors and partners] will come. Each donor or partner wants results. With results, then they will come. It's not complicated," an internal stakeholder explained.

\section{DISCUSSION}

Factors influencing national political priority for micronutrient deficiencies

This qualitative study identified several factors affecting the political prioritisation process for MNDs from the perspective of key experts working in this field. In doing so, it offers some explanation as to why the issue of MNDs has struggled to gain political attention and make it onto the policy agenda. Interestingly, this study also identified that the perceived level of political priority for MNDs varied considerably between key stakeholders involved in the field of nutrition and health in Senegal. This may reflect the perceptions of the individuals representing these organisations, or may be the result of, or consequence of, how the issue of MNDs is understood and framed by the national policy community. This qualitative analysis therefore raises questions about the complex relationship between perceptions of political priority and the agenda-setting process for MNDs.

Relating the study's findings to the existing theoretical literature yields additional insights. For an issue to gain political priority on the government agenda, Kingdon's theory of agenda setting argues that three independent streams need to converge: the problem stream, where an issue becomes perceived as a problem that needs to be and can be addressed compared with other competing priorities; the policy stream, where alternative policy solutions are proposed to address the problem; and the politics stream, where political events create a window of opportunity for policy reform. ${ }^{10}$

In this case, in the problem stream, credible indicators that objectively quantified the severity of the issue were used by the policy community to highlight the prevalence of MNDs. This was supported by advocacy efforts that used calculations of disability-adjusted life years lost due to MNDs and the benefit: cost ratios to support investing in reducing MNDs. However, several factors impeded progress-these mainly relate to the characteristics of the problem or issue itself. First, the 'hiddenness' of MNDs diminished the visibility of this issue, posing a challenge to MNDs commanding the sustained attention of civil society and policymakers. This is in contrast, for example, to HIV/AIDS where the impact on people, societies and economies is highly visible, and facilitated generating attention and support for the issue. ${ }^{22}$ Second, the typical chronic nature of MNDs does not command a sense of urgency to act, for example compared with acute epidemics or famines. Third, although global evidence to support effective interventions was available, the lack of country-level evidence and inability to demonstrate clear results from policy and programmatic actions impeded advocacy efforts to address the issue. Policymakers, in order to get behind the issue need to be convinced of its feasibility, with investment in political capital bringing about positive results rather than taking the risk of backing more complex or challenging issues.

In the policy stream, we see that the policy community, although diverse, was cohesive. All stakeholders commented on the collective efforts in advocating for MNDs, and how this strengthened their ability, harnessing their individual strengths, to champion the issue. It was also opportune to champion all MNDs together as one group, rather than individual deficiencies. However, two impeding factors were identified. First, the institutional weakness of the lead ministry, which lacked resources and capacity to take on this issue; and second, the complexity of the policy solutions required to address MNDs. Stakeholders were in agreement that a multisectoral response with multiple solutions was required, with the need for multistakeholder involvement to address different MNDs. This added another layer of complexity, technically and operationally, to delivering an effective multifaceted response. In the Senegalese setting, there were difficulties in ensuring the timeliness, accuracy and completeness of data to demonstrate the effectiveness of policy responses. This was compounded by the limited leadership capacity of the lead ministry to coordinate stakeholders and activities, to maximise the potential of such partnerships and to bring other ministries to the table to tackle the issue.

In the politics stream, no clear political transitions were discussed by stakeholders that could present a window of opportunity for reform. Nor was there evidence of a policy advocate, a person who was actively championing the issue of MNDs, or of civil society organisations pushing for this problem to be addressed. The concentration of MNDs among vulnerable groups of women and children is critical: these groups are less politically empowered and have limited electoral power to command priority from policymakers. Furthermore, as many of those afflicted by MNDs are unaware of the disease burden, it is even more challenging to mobilise interest groups around this issue.

As a result of the impeding factors in each stream, this analysis demonstrates why MNDs have failed to sustainably command the attention of decision makers. Application of Kingdon's theory provides a useful framework for analysis; however, it has limitations. First, as it is 
based on national agenda setting in the context of the American political system, it may not capture the different dynamics and complexity of political systems in lowincome and middle-income countries. ${ }^{23}$ Second, as this study demonstrates, it is perhaps oversimplistic: facilitating and impeding factors often overlap and interact between in the three streams, and the agenda-setting stage of the policy cycle may also interact with other stages, such as implementation. Third, this theory of national agenda setting does not include interactions between global agenda-setting activities and nationallevel processes.

\section{Global agenda-setting activities influencing national policy processes}

The importance of global agenda-setting activities at the national level was a key theme emerging from this analysis. This theme has been raised in the applied literature examining the priority of global health issues on national agendas. ${ }^{11}$ 24-26 Shiffman highlighted the importance of 'transnational influences' whereby norm promotion and resource provision can influence the degree to which an issue appears on the national agenda. $^{11}$

In the case of MNDs in Senegal, several themes around global influences were highlighted. First, was the use of globally accepted evidence on effective solutions for MNDs (e.g. Lancet series on maternal and child nutrition), which resonated well with the policy community, giving them cogent arguments to support their advocacy effort with decision makers. Second, was the impact of donor funding on influencing national priorities. Stakeholders commented on the role of external donors shaping the agenda through their own priorities and resource allocation. Donor agendas were purported to undermine the empowerment of the ministry to take charge of deciding which competing priorities should receive funding allocation. Third, was the influence of global advocacy for MND: the local launch of the Call to Action on Vitamin and Mineral Deficiencies provided a forum to garner support and galvanise how the issue was framed among the policy community and to broader audiences, including the private sector, who through public-private partnerships, particularly those relating to food fortification, have an important role to play in addressing MNDs. Although the issue of MND gained the attention of policymakers at the time of the launch, none of the internal stakeholders thought that this had impact: the challenge of translating this event into sustained political prioritisation for MNDs remained.

\section{Limitations}

This qualitative study has limitations. As with all case studies, it is not possible to generalise these findings to other contexts. However, it is likely that many of the findings are transferable to other settings, particularly the broader themes relating to issue characteristics and issue complexity of MNDs. In other low-income and middle-income countries burdened with MNDs, several of the other themes may also resonate, such as those relating to multisectoral coordination required to deliver solutions and advocacy through a policy champion or entrepreneur. Second, are issues relating to the study methodology. Not all interviews were recorded, which may have limited the ability to delineate nuances available from transcribed interviews. Also, due to operating in two languages at times, some subtle understanding of issues may not have been clearly denunciated, especially as many of the participants were not using their native language. Although stakeholders interviewed for this study represent the array of institutions working in micronutrients, it may be possible that other representatives from these same institutions or other institutions or sectors, such as from finance and agriculture, could have added further insights to the study's findings. No representative from the private sector was interviewed due to logistical reasons, which was an omission. Also, the data collection and analysis were conducted in 2010, so the study findings may be less relevant to today's context. Third, the author's positionality having been introduced with a letter of introduction from the lead ministry, and being an outsider may have affected how participants responded. Moreover, personal connections through shared disciplinary backgrounds (physicians or researchers) with different participants may have differentially altered their responses, for example, greater openness with the author because of shared bonds. Fourth, as the data collection and analysis were carried out by one researcher, this may have increased the likelihood of bias. To mitigate this, interview transcripts were independently reviewed by other researchers to confirm the reliability of the coding and themes emerging from the data.

\section{Implications of the study}

This analysis does offer some insight into the factors affecting agenda setting, which could help with devising political strategies to help prioritise addressing MNDs, at national and global levels. An interesting finding was that many stakeholders interviewed were not acutely cognisant of political process relating to agenda setting for health policy, and were interested in this research question and the potential implications of this research. To this end, it is also important for the policy and technical community to be aware of the politics around the policy process and build capacity to navigate the political policy process. ${ }^{27}$ This could take advantage of the methods and tools that already exist to conduct a political analysis for food and nutrition security, ${ }^{26}$ and generate recommendations to enhance the political feasibility of efforts to champion MNDs. This study revealed the absence of a political strategy to advance prioritisation of MNDs.

Some broad recommendations to increase the political priority of MNDs could include actions to identify and support a champion to strongly advocate for MNDs; promote greater awareness of MNDs among civil society, for example, through education activities or mass and 
social media; support policy communities to devise strategies that best capitalise on their collective strengths to nudge national officials to commit to specific actions; take advantage of focusing events nationally and globally that could promote the issue; focus on carefully monitoring and evaluating MND policies and programmes and documenting successes, so as to demonstrate effective and feasible policy solutions to highlight to policymakers. These general strategies would need to be tailored to the specific context and policy environment around MNDs.

\section{Future study of political prioritisation processes for global health issues}

This study contributes to the growing literature that attempts to understand the variation in the priority and attention granted to different global health issues, using the hitherto unstudied case study of MNDs. As more and more global and national actors vie to promote priority for their valued issues, the process of priority setting at the national level is becoming increasingly complex. This raises a number of questions and issues. On an academic level, it exposes the shortcoming of existing theories to understand the policy process for global health, with need to develop theories or adapt existing theories to help shape our understanding of global health agenda setting. On a practical level, it raises the broader issue of the implications of separate or uncoordinated efforts to promote different agendas within global health. While there are advantages in advocating for specific issues, it is not clear whether fragmented advocacy efforts in nutrition, for example, for MNDs or breastfeeding or child overweight and obesity, detract from bringing about more integrated and coordinated progress in nutrition or development more broadly. Moreover, it is unknown whether competing priorities vying for attention result in 'attention fatigue' and whether national policymakers become refractory to repeated calls to action. Further theoretical and applied work could explore these issues.

Acknowledgements The author expresses thanks to the key experts who kindly participated in this study and the Council of Women World Leaders. In addition, the author would like to thank Vanessa Fong, Christina Smiraglia and classmates at the Harvard Graduate School of Education for verifying the data analysis and reviewing earlier drafts of this paper; and Ashley Fox and Michael Reich for rich discussions on applied political economy analysis. Finally, the author thanks Donald Halstead for thoughtful comments that greatly enhanced this paper.

Funding This research received no specific grant from any funding agency in the public, commercial or not-for-profit sectors.

Competing interests The author was a recipient of a Fellowship from the Council of Women World Leaders, Washington DC. YB had full access to all of the data in the study and can take responsibility for the integrity of the data and the accuracy of the data analysis.

Ethics approval This study was approved by the Institutional Review Board of the Harvard School of Public Health. Protocol \#: 19491-101.

Provenance and peer review Not commissioned; externally peer reviewed.

Data sharing statement No additional data are available.

Open Access This is an Open Access article distributed in accordance with the Creative Commons Attribution Non Commercial (CC BY-NC 3.0) license, which permits others to distribute, remix, adapt, build upon this work noncommercially, and license their derivative works on different terms, provided the original work is properly cited and the use is non-commercial. See: http:// creativecommons.org/licenses/by-nc/3.0/

\section{REFERENCES}

1. UNICEF. Improving child nutrition: the achievable imperative for global progress. New York, NY: UNICEF, 2013:18.

2. Micronutrient Initiative. Investing in the future: a united call to action on vitamin and mineral deficiencies. Ottawa: Micronutrient Initiative, 2009.

3. Ezzati M, Lopez AD, Rodgers AA, et al. Comparative quantification of health risks: global and regional burden of disease attributable to selected major risk factors. Geneva: World Health Organization, 2004.

4. Murray CJ, Vos T, Lozano R, et al. Disability-adjusted life years (DALYs) for 291 diseases and injuries in 21 regions, 1990-2010: a systematic analysis for the Global Burden of Disease Study 2010. Lancet 2012;380:2197-223.

5. Boy E, Mannar V, Pandav C, et al. Achievements, challenges, and promising new approaches in vitamin and mineral deficiency control. Nutr Rev 2009;67:S24-30.

6. Copenhagen Consensus. Expert panel findings. Copenhagen Consensus 2012. Washington DC: Copenhagen Consensus Center, 2012.

7. Agence Nationale de la Statistique et de la Démographie (ANSD) [Sénégal] ell. Enquête Démographique et de Santé à Indicateurs Multiples au Sénégal (EDS-MICS) 2010-2011. Calverton, Maryland, USA: ANSD et ICF International, 2012.

8. Walt G, Shiffman J, Schneider $\mathrm{H}$, et al. 'Doing' health policy analysis: methodological and conceptual reflections and challenges. Health Policy Plan 2008;23:308.

9. Shiffman J, Smith S. Generation of political priority for global health initiatives: a framework and case study of maternal mortality. Lancet 2007;370:1370-9.

10. Kingdon J. Agendas, alternatives, and public policies. Longman Classics Edition. Longman Publishing Group, 2002.

11. Shiffman J. Generating political priority for maternal mortality reduction in 5 developing countries. Am J Public Health 2007;97:796-803.

12. Shiffman J. Issue attention in global health: the case of newborn survival. Lancet 2010;375:2045-9.

13. Geneau R, Stuckler D, Stachenko S, et al. Raising the priority of preventing chronic diseases: a political process. Lancet 2010;376:1689-98.

14. Shiffman J. Generating political will for safe motherhood in Indonesia. Soc Sci Med 2003;56:1197-207.

15. Hafner T, Shiffman J. The emergence of global attention to health systems strengthening. Health Policy Plan 2013;28:41-50.

16. Shiffman J, Quissell K. Family planning: a political issue. Lancet 2012;380:181-5.

17. Micronutrient Initiative. Investing in Senegal's future: a united call to action on vitamin and mineral deficiencies. News article.19 Jan 2010. Available at, http://www.micronutrient.org/English/view.asp? $\mathrm{x}=656$ \&id=37. Accessed Jul 2014.

18. Bennett AA. Case studies and theory development in the social sciences. Mit Press, 2005.

19. Glaser BG, Strauss AL. The discovery of grounded theory: strategies for qualitative research. Transaction Books, 2009.

20. Shekar M, Heaver R, Lee Y-K. Repositioning nutrition as central to the development agenda: a strategy for large scale action. World Bank-free PDF, 2005

21. Natalicchio M. Carrots and sticks: the political economy of nutrition policy reforms. World Bank, 2009.

22. Shiffman J. HIV/AIDS and the rest of the global health agenda. Bull World Health Organ 2006;84:923.

23. Court J, Young J. Bridging research and policy: insights from 50 case studies. Overseas Development Institute (ODI), 2003.

24. Reich MR. The politics of agenda setting in international health: child health versus adult health in developing countries. J Int Dev 1995;7:489-502.

25. Shiffman J, Smith S. Generation of political priority for global health initiatives: a framework and case study of maternal mortality. Lancet 2007;370:1370-9.

26. Reich MR, Balarajan Y. Political Economy Analysis for Food and Nutrition Security. HNP Discussion Paper. Washington, DC: World Bank, 2012.

27. Fox A, Reich M, eds. Political economy of reform: the art of the feasible. Washington DC: World Bank Publications, 2013. 